${ }^{1}$ Department of Forensic Dentistry, Piracicaba Dental School, University of Campinas, São Paulo, Brazil.

${ }^{2}$ Forensic Expert, Police Department of Federal District, Brazil.

${ }^{3}$ National Museum, Federal University of Rio de Janeiro, Rio de Janeiro, Brazil.

${ }^{4}$ Forensic Expert, Police Department of Minas Gerais, Brazil.

${ }^{5}$ Department of Forensic Dentistry, University of São Paulo, Brazil.

${ }^{6}$ Department of Forensic Dentistry, Federal University of Paraiba, Brazil.

Corresponding author:

Rachel Tinoco

Email: rachelrtinoco@gmail.com

Received: July 25, 2020

Accepted: January 22, 2021

\section{Sex dimorphism according to the nasozygomatic triangle}

\author{
Fábio Delwing ${ }^{1,2}$ iD, Rachel Lima Ribeiro Tinoco ${ }^{3,{ }^{*}}$ (iD, \\ Geraldo Elias Miranda ${ }^{1,4,5}$ (iD, Laíse Nascimento \\ Correia Lima $^{1,6}$ (iD), Luiz Francesquini Júnior ${ }^{1}$ (iD), \\ Eduardo Daruge Júnior ${ }^{1}$
}

Sex is one of the first features to be diagnosed in human identification, composing, with age, ancestry and stature, the so called "big four". Aim: The present study aimed to metrically analyze the sexual dimorphism in skulls of known age and sex from Rio Grande do Sul - Brazil. Methods: This was a crosssectional study of metrical analysis, which used a sample comprised of 209 human skulls (106 male and 103 female) older than 22 years old at the time of death, undamaged and without signs of trauma or abnormalities. The point nasion and the most superior points on the zygomaticotemporal sutures from each side were connected forming a triangle. This area was calculated using Heron's formula, and the results were submitted for statistical analysis. Results: All measurements showed significant values for sexual dimorphism. Through the area of the triangle, it was possible to determine sex with an accuracy of $83.97 \%$ for males and $83.50 \%$ for females. Conclusion: This simple method requires only a caliper, and still can be reliable for forensic human identification. It must be diffused and tested on other samples, and can be used as a good and inexpensive tool for experts in day-to-day practice.

Keywords: Forensic anthropology. Sex determination by skeleton. Sex characteristics. Skull. 


\section{Introduction}

Historically, human identification is one of the biggest challenges faced by forensic science. The existence of sexual dimorphism in human skeletons and its importance in investigative methods has long been recognized. Krogman and Íscan ${ }^{1}$ asserted that sex assessment was possible, with levels of reliability of $100 \%$ when the entire skeleton is present, $92 \%$ using the skull alone, and $98 \%$ when combining pelvis and skull. Together with pelvic bones, the skull remains among the most dimorphic segments of the skeleton, although this determination has its reliability totally established only after puberty ${ }^{2,3}$.

Morphological analysis, being an even faster process, brings a high degree of subjectivity, decreasing its reliability. For this reason, metric techniques, being intrinsically more objective, can offer a better data achievement, with less variability between experts ${ }^{1,4,5}$.

Craniofacial structures have the advantage of being composed largely of hard tissue with a higher resistance to decomposition ${ }^{6}$, allowing their analysis even after mass disasters, or other forms of violence. Krogman and Iscan ${ }^{1}$ and Meindl et al. ${ }^{7}$ have stressed that anatomical variations are population-dependent, and any method for human identification should be tested and validated in the target population, prior to being used.

Patil and Mody ${ }^{8}$ claim that large and robust skulls tend to be male, and delicate skulls tend to be female. To Kranioti et al. ${ }^{9}$, the males are statistically larger in all their dimensions in relation to females. Several authors concluded in their research, among different craniometric points analyzed, that the bizygomatic distance exhibited a high degree of sexual dimorphism ${ }^{9-11}$. The purpose of this study was to evaluate the accuracy of a new sexing method using the area of the triangle formed from the measurements of three craniometrics points in the upper face of skulls.

\section{Materials and Methods}

This research was conducted in the city of Porto Alegre, Rio Grande do Sul Brazil, after being approved by the Ethics Committee of the Faculty of Dentistry of Piracicaba, UNICAMP, São Paulo - Brazil, approval number 138/2010. The sample consisted of 209 skulls (106 males and 103 females) selected by convenience during six months of data collection, according to the routine exhumations of the cemetery. Individuals from 22 years of age or older at time of death were included, to ensure full development of the skull and end of facial growth. Exclusion criteria were any kind of trauma, visible anomalies, or post-mortem damage, like bone breaking or cracking during exumation, that could interfere with the measurements taken. The possibility of edentulism was not an exclusion criterion, since the presence or absence of teeth does not influence the used measures. Sex verification was ensured by the burial records and codified to allow a blind analysis. 
The metric analysis of the skulls was performed by a single examiner previously calibrated after measuring 50 skulls, with a digital caliper (Mitutoyo, São Paulo - Brazil), and registered in an Excel sheet. The data consisted of the measurements between nasion (point $\mathrm{N}$ ) and the most superior point of the zygomatic-temporal suture on both sides - which was called, for this study, zygomatic-temporal point (point ZT). Table 1 shows the measurement abbreviations and definitions, and Figure 1 shows their representations on the skull.

Table 1. Abbreviation and definition of the measures taken

\begin{tabular}{lc}
\hline Measure & Definition \\
\hline $\mathrm{N}-$ ZT.R & From nasion to the most superior point of the zygomatic-temporal suture on the right side \\
\hline $\mathrm{N}-\mathrm{ZT}$.L & From nasion to the most superior point of the zygomatic-temporal suture on the left side \\
\hline ZT.R - ZT.L & Between the most superior point of the zygomatic-temporal suture from right to left sides \\
\hline
\end{tabular}
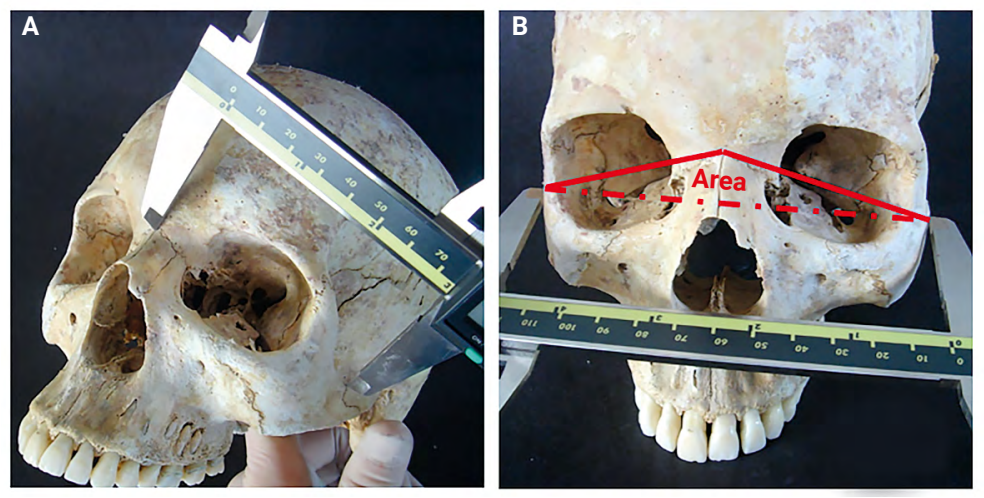

Figure 1. Measure taken from nasion to point ZT.L (A); and graphic representation of the triangle formed by the three points $(B)$.

After the three measurements had been taken, the triangle formed by their connection (Figure 1) had its area calculated by Heron's formula ${ }^{12}$. This is used in plane geometry to determine the area of a triangle when only the length of the sides $a, b$ and $c$ are known, as shown below:

$$
\text { Triangle area }=\sqrt{s(s-a)(s-b)(s-c)} \text {, in which } s=\frac{a+b+c}{2}
$$

The area of the proposed nasozygomatic triangle can only be calculated by this formula, since the triangle has its base backwards from its apex, making it an angled figure relative to the anatomic coronal plane.

The measurements taken were subjected to Student t-test $(p<0.001)$ for assessment of sexual dimorphism. In order to test for intra-examiner error, the skulls of $20 \%$ of the sample were randomly selected, including both sexes, and were analyzed twice, within a two week interval. The two sets of values for these individuals were compared by means of a paired Students't-test, showing non statistically significant difference $(p>0.05)$. 


\section{Results}

For the three measurements taken from the sample (209 skulls), and the triangle area calculated by their connection, sexual dimorphism was statistically significant $(p<0.001)$ in all values, as shown in Table 2. On analyzing the ratio between the male and female average of the measurements and triangle area, the male average was always higher than the female, thereby showing relevant sexual dimorphism of this anatomic triangle, as shown in Table 3.

Table 2. Student t-test with average male and female and their minimum and maximum limits

\begin{tabular}{lccccccc}
\hline & \multicolumn{5}{c}{ Male } & \multicolumn{5}{c}{ Female } \\
\cline { 2 - 8 } & mean (SD) & $\min$ & $\max$ & $\operatorname{mean}(\mathrm{SD})$ & $\min$ & $\max$ & $\mathbf{p}$ \\
\hline $\mathrm{N}-$ ZT.R $(\mathrm{mm})$ & $76.67(4.207)$ & 75.866 & 77.487 & $71.546(2.896)$ & 70.988 & 72.104 & $<0.001^{*}$ \\
\hline $\mathrm{N}-\mathrm{ZT} . \mathrm{L}(\mathrm{mm})$ & $76.857(4.395)$ & 76.011 & 77.704 & $71.606(2.861)$ & 71.054 & 72.157 & $<0.001^{*}$ \\
\hline ZT.R-ZT.L $(\mathrm{mm})$ & $117.998(5.368)$ & 116.964 & 119.031 & $111.117(4.344)$ & 110.280 & 111.954 & $<0.001^{*}$ \\
\hline Area $\left(\mathrm{mm}^{2}\right)$ & $\begin{array}{l}2,896.006 \\
(338.470)\end{array}$ & $2,830.821$ & $2,961.191$ & $\begin{array}{l}2,503.607 \\
(200.644)\end{array}$ & $2,464.952$ & $2,542.262$ & $<0.001^{*}$ \\
\hline
\end{tabular}

* all significant at $p<0.001$

Table 3. Quotient between male and female average

\begin{tabular}{lccl}
\hline & Quotient & $\%$ & Interpretation \\
\hline $\mathrm{N}-$ ZT.R & 1.072 & 7.20 & average male $7.2 \%$ higher than female \\
\hline $\mathrm{N}-\mathrm{ZT} . \mathrm{L}$ & 1.073 & 7.30 & average male $7.3 \%$ higher than female \\
\hline ZT.R - ZT.L & 1.062 & 6.20 & average male $6.2 \%$ higher than female \\
\hline Triangle area & 1.157 & 15.7 & average male $15.7 \%$ higher than female \\
\hline
\end{tabular}

Figure 2 shows a diagram with the range of the triangle area for males and females. To obtain it, the average area of the triangle for each sex and their respective standard deviation was used. From that, it can be said that if the triangle area value is lower than $2,558 \mathrm{~mm}^{2}$, the skull is female; if the value is greater than $2,703 \mathrm{~mm}^{2}$, it is male. However, if the value is between $2,558 \mathrm{~mm}^{2}$ and $2,703 \mathrm{~mm}^{2}$, the method does not contribute to sex diagnosis, since this range was found to be doubtful. Skulls with nasozygomatic triangle area greater than $3,234 \mathrm{~mm}^{2}$ were considered hypermales, and those with area below 2,303 $\mathrm{mm}^{2}$ were considered hyperfemales, as can be seen in Figure 2 .

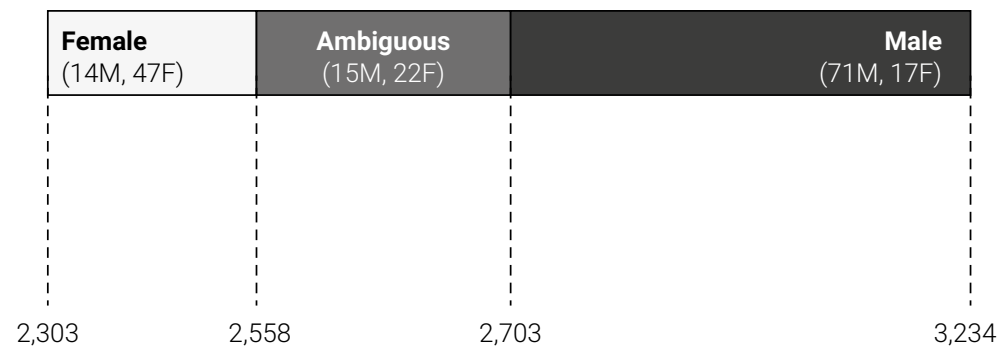

Figure 2. Sex diagnosis according to the nasozigomatic triangle area (in $\mathrm{mm}^{2}$ ) 
For skulls with this triangle area higher than $2,703 \mathrm{~mm}^{2}$, or lower than $2,558 \mathrm{~mm}^{2}$, this sexing method has a reliability of $83.97 \%$ for males and $83.50 \%$ for females, respectively, as shown in Table 4. Intra-observer error showed non-significant values between the two groups of measures ( $p=0.773$ for $N-Z T$.R; $p=0.100$ for $N-Z T$.L; and $p=0.266$ for ZT.R - ZT.L).

Table 4. Sex determination accuracy and area values for male and female

\begin{tabular}{lcc}
\hline Area $\left(\mathrm{mm}^{2}\right)$ & Sex & Accuracy \\
\hline$>2,703$ & Male & $83.97 \%$ \\
\hline$<2,558$ & female & $83.50 \%$ \\
\hline
\end{tabular}

\section{Discussion}

Forensic anthropologists are continually challenged by the human identification issue, and develop new methods or improve the accuracy of existing ones, applied on various parts of the skeleton so that the method can be admissible in court ${ }^{10,13,14}$.

It is known that anthropological research is more susceptible to errors when purely morphological criteria are considered, due to phenotypic variations, pathological signs and even according to the observer, making the analysis undesirably subjective. Thus, a quantitative method, for its objectivity and reproducibility by any researcher and expert, can join to the group of procedures for human identification, with accuracy and reliability ${ }^{5,8}$.

In a forensic anthropological analysis of a skeleton, with identification as its primary aim, sex is one of the first and most important piece of information to be obtained, being part of the so called "big four", together with age, stature, and ancestry ${ }^{15-17}$. Human bones have low sexual dimorphism, if compared with other primates ${ }^{18}$; still, the most dimorphic parts of the skeleton is the pelvis, followed by the skull. Therefore, whenever the pelvis is not available, sexing methods must be based on cranial anatomy ${ }^{1,5}$. The percentage of correct answers regarding sex diagnose based exclusively on skull features range from $70.56 \%$ to $92 \% 7,19$. Results obtained in this study, using the area of the proposed nasozygomatic triangle (in $\mathrm{mm}^{2}$ ) reached a reliability of $83.97 \%$ for males and $83.50 \%$ for females.

Before puberty, sexual characteristics are not very pronounced; it is only after this period, under hormonal influence, environment and muscles, that the human skeleton begins to show sexual dimorphism. Due to this, in this study, as inclusion criteria, only skulls of individuals aged from 22 years old and up at time of death were analyzed.

Mainly due to the variation between groups of different ancestries, the methods of identification in forensic anthropology must be regionalized and validated for specific populations. This is the reason why previous studies should test and find the reliability of a given method in their respective target population, so that it can be used for human identification ${ }^{5,7}$. Craniometric traits show a level of regional differentiation comparable to genetic markers, with high levels of variation within populations as 
well as a correlation between phenotypic expression and geographic distance, which allows high levels of classification reliability when comparing skulls from different parts of the world ${ }^{20}$.

The Brazilian population has a high degree of biological variation. This is due to the hybridization of the Amerindians as first settlers with European and Sub-Saharan groups, after colonization occurred in the $16^{\text {th }}$ century, which was studied by Ross et al. ${ }^{21}$, and stressed by Urbanová et al. ${ }^{22}$. This showed higher misclassification of sex and ancestry for the Afro-Brazilian sample, according to software tools. It also must be noted that genetic marker studies ${ }^{23,24}$, showed a regional variation according to the mtDNA lineages, with high European influence in the Southern region, where this study was performed. The use of craniometric methodology published in tables and indexes from studies of foreign authors or other regions of Brazil must be cautious, and craniometric variations for any method should be validated, for forensic purposes.

Large and robust skulls tend to be male, and delicate skulls tend to be female ${ }^{8}$. As known from anthropological studies, males skulls are statistically higher in all their dimensions in relation to females ${ }^{9}$. This study also observed the preponderance of all measures in males. The average area of the nasozygomatic triangle in males was $15.7 \%$ higher than females.

Among the measurements, bizygomatic width was classified as the most dimorphic measure for sex diagnosis ${ }^{9,10}$. After this, measurements of the upper portion of the facial skull have also been shown as sexually dimorphic ${ }^{11}$. This study used craniometric measurements of the upper face in search of this dimorphism reported in literature, and applied a new method to examine an old issue in forensic anthropology: sexual diagnosing by use of the skull. The use of techniques such as computerized tomography ${ }^{25}, 3 \mathrm{D}$ graphics ${ }^{26}$, and morphometric geometry ${ }^{27}$ can be very helpful, but if a simple method that requests only a caliper and can still be reliable for forensic human identification, it must be diffused and tested on other samples. The accuracy of the cutoff points showed that the method can be used as a good and inexpensive tool for experts in day-to-day practice, dealing with unidentified individuals.

However, the predictive values (sensitivity, specificity, positive predictive value, negative predictive value, and likelihood ratio) were not calculated, and can be investigated by future researchers. In skulls that show results between $2,558 \mathrm{~mm}^{2}$ and $2,703 \mathrm{~mm}^{2}$ the method does not contribute to sexual diagnosis, which was considered as a limitation, as well as skulls younger than 22 years old, not included in the sample. Future projects should also consider the possibility of adapting the method for children and young adults.

To conclude, the proposed method uses points which are easily identifiable and of rapid measurement, with which experts can diagnose sex when only the skull is available. If the value found of the nasozygomatic triangle area is within the doubtful range, nothing can be said about sex by the proposed technique; however, if this value is not between $2,558 \mathrm{~mm}^{2}$ and $2,703 \mathrm{~mm}^{2}$, sex information can be achieved with a reliability of $83.97 \%$ for males and $83.50 \%$ for females. 


\section{References}

1. Krogman W, Iscan MY. The human skeleton in forensic medicine. $2^{\text {nd }}$ ed. Springfield: Charles C Thomas; 1986

2. Christensen AM, Passalacqua NV, Bartelink EJ. Sex Estimation. In: Christensen AM, Passalacqua NV, Bartelink EJ. Forensic anthropology: current methods and practice. Cambridge: Academic Press; 2019. p.243-70. doi: 10.1016/B978-0-12-815734-3.00008-7

3. Klales AR, editor. Sex estimation of the human skeleton: history, methods, and emerging techniques. Cambridge: Academic Press; 2020.

4. Walrath DE, Turner P, Bruzek J. Reliability test of the visual assessment of cranial traits for sex determination. Am J Phys Anthropol. 2004;125(2):132-7. doi: 10.1002/ajpa.10373.

5. İşcan MY. Forensic anthropology of sex and body size. Forensic Sci Int. 2005;147(2-3):107-12. doi.org/10.1016/j.forsciint.2004.09.069

6. Latham KE, Baterlink EJ, Finnegan M. New perspectives in forensic human skeletal identification. Cambridge: Academic Press; 2017.

7. Meindl RS, Lovejoy CO, Mensforth RP, Don Carlos L. Accuracy and direction of error in the sexing of the skeleton: implications for paleodemography. Am J Phys Anthropol. 1985;68(1):79-85 doi.org/10.1002/ajpa.1330680108.

8. Patil KR, Mody RN. Determination of sex by discriminant function analysis and stature by regression analysis: a lateral cephalometric study. Forensic Sci Int. 2005;147(2-3):175-80. doi.org/10.1016/j.forsciint.2004.09.071.

9. Kranioti EF, Işcan MY, Michalodimitrakis M. Craniometric analysis of the modern Cretan population. Forensic Sci Int. 2008;180(2-3):110.e1-5. doi.org/10.1016/ j.forsciint.2008.06.018.

10. Steyn M, Işcan MY. Sexual dimorphism in the crania and mandibles of South African whites. Forensic Sci Int. 1998;98(1-2):9-16. doi.org/10.1016/S0379-0738(98)00120-0.

11. Naikmasur VG, Shrivastava R, Mutalik S. Determination of sex in South Indians and immigrant Tibetans from cephalometric analysis and discriminant functions. Forensic Sci Int. 2010;197(1-3):122.e1-6. doi.org/10.1016/j.forsciint.2009.12.052.

12. Pappas T. Heron's Theorem. In: Pappas T. The joy of mathematics. San Carlos: Wide World Publishing/Tetra; 1989. p.62.

13. Rogers TL. Determining the sex of human remains through cranial morphology. J Forensic Sci. 2005;50(3):493-500.

14. Williams BA, Rogers T. Evaluating the accuracy and precision of cranial morphological traits for sex determination. J Forensic Sci. 2006;51(4):729-35. doi: 10.1111/j.1556-4029.2006.00177.x.

15. Gill GW. Craniofacial criteria in the skeletal attribution of race. In: Reichs KJ, editor. Forensic osteology: advances in the identification of human remains. $2^{\text {nd }}$ ed. Springfield: Charles C Thomas; 1998. p.293-315.

16. White TD, Black MT, Folkens PA. Human osteology. San Diego. Academic Press; 2011.

17. Byers SN. Introduction to forensic anthropology: a textbook. Boston: Allyn and Bacon; 2002.

18. Stanford C, Allen JS, Antón SC. Biological anthropology: the natural history of humankind. London: Pearson Education; 2016.

19. Đurić $M$, Rakočević Z, Đonić $D$. The reliability of sex determination of skeletons from forensic context in the Balkans. Forensic Sci Int. 2005;147(2-3):159-64. doi: 10.1016/j.forsciint.2004.09.111.

20. Relethford JH. Race and global patterns of phenotypic variation. Am J Phys Anthropol. 2009;139(1):16-22. doi: 10.1002/ajpa.20900. 
21. Ross $A H$, Ubelaker $D H$, Falsetti $A B$. Craniometric variation in the Americas. Hum Biol. 2002;74(6):807-18. doi: 10.1353/hub.2003.0010.

22. Urbanová P, Ross AH, Jurda M, Nogueira MI. Testing the reliability of software tools in sex and ancestry estimation in a multi-ancestral Brazilian sample. Leg Med Tokyo. 2014;16(5):264-73. doi: 10.1016/j.legalmed.2014.06.002.

23. Pena SDJ. [Retrato molecular do Brasil]. Cienc Hoje. 2000;27(159):16-25. Portuguese.

24. Alves-Silva J, da Silva Santos M, Guimarães PEM, Ferreira AC, Bandelt HJ, Pena SD, et al. The ancestry of brazilian mtDNA lineages. Am J Hum Genet. 2000;67(2):444-61. doi: 10.1086/303004.

25. Gulhan O, Harrison K, Kiris A. A new computer-tomography-based method of sex estimation: Development of Turkish population-specific standards. Forensic Sci Int. 2015;255:2-8. doi: 10.1016/j.forsciint.2015.07.015.

26. Mediavilla ER, Pérez BP, González EL, Sánchez JAS, Fernández ED, Sáez AS. Determining sex with the clavicle in a contemporary Spanish reference collection: A study on 3D images. Forensic Sci Int. 2016;261:163.e1-163.e10. doi: 10.1016/j.forsciint.2016.01.029.

27. Cavaignac E, Savall F, Faruch M, Reina N, Chiron P, Telmon N. Geometric morphometric analysis reveals sexual dimorphism in the distal femur. Forensic Sci Int. 2016;259:246.e1-246.e5.

doi: 10.1016/j.forsciint.2015.12.010. 